\title{
A spatially explicit individual-based model to support management of commercial and recreational fisheries for European sea bass Dicentrarchus labrax
}

Article

Accepted Version

Creative Commons: Attribution-Noncommercial-No Derivative Works 4.0

Walker, N. D., Boyd, R., Watson, J., Kotz, M., Radford, Z., Readdy, L., Sibly, R., Roy, S. and Hyder, K. (2020) A spatially explicit individual-based model to support management of commercial and recreational fisheries for European sea bass Dicentrarchus labrax. Ecological Modelling, 431. 109179. ISSN 0304-3800 doi:

https://doi.org/10.1016/j.ecolmodel.2020.109179 Available at https://centaur.reading.ac.uk/91273/

It is advisable to refer to the publisher's version if you intend to cite from the work. See Guidance on citing.

To link to this article DOI: http://dx.doi.org/10.1016/j.ecolmodel.2020.109179

Publisher: Elsevier

All outputs in CentAUR are protected by Intellectual Property Rights law, including copyright law. Copyright and IPR is retained by the creators or other copyright holders. Terms and conditions for use of this material are defined in the End User Agreement. 


\section{www.reading.ac.uk/centaur}

\section{CentAUR}

Central Archive at the University of Reading

Reading's research outputs online 


\section{A spatially explicit individual-based model to support}

2 management of commercial and recreational fisheries for

3 European sea bass Dicentrarchus labrax

4 Nicola D. Walker ${ }^{1, *}$, Robin Boyd ${ }^{2}$, Joseph Watson ${ }^{3}$, Max Kotz $^{4}$, Zachary Radford ${ }^{1}$, Lisa

5 Readdy $^{1}$, Richard Sibly ${ }^{3}$, Shovonlal Roy ${ }^{2}$ and Kieran Hyder ${ }^{1,5}$

6

$7 \quad{ }^{1}$ Centre for Environment, Fisheries and Aquaculture Science, Lowestoft Laboratory, 8 Lowestoft, NR33 OHT, UK

9

2Department of Geography and Environmental Science, University of Reading, Whiteknights, Reading, RG6 6AB, UK

${ }^{3}$ School of Biological Sciences, University of Reading, Whiteknights, Reading, RG6 $6 \mathrm{AB}, \mathrm{UK}$

${ }^{4}$ Department of Environmental Science and Engineering, California Institute of Technology, Pasadena, CA 91125

${ }^{5}$ School of Environmental Sciences, University of East Anglia, Norwich Research Park, Norwich, Norfolk NR4 7TJ, UK

*Correspondence: nicola.walker@cefas.co.uk

\section{Abstract}

The European sea bass (Dicentrarchus labrax) is a slow growing and late maturing high value fish that is exploited by both commercial and recreational fisheries. In recent years, scientific assessments have shown a rapid decline in spawning stock 
biomass around the UK attributed to poor recruitment (driven by environmental factors) and high fishing mortality. This resulted in significant reductions in the harvest of sea bass following technical measures implemented by the European Commission to conserve stocks. Individual-based models (IBMs) are simulations of individual 'agents' of organisms that interact with each other and their environment locally and have been shown to be effective management tools in many systems. Here, an IBM that simulates the population dynamics and spatial distribution of sea bass was developed to assess how technical management measures applied to subsets of the population impact the overall stock. Conventional stock assessment techniques were used to model the processes affecting population dynamics, while the spatial distribution was simulated using a combination of temperature preferences and information from tagging studies. The IBM was parameterised using existing knowledge from the literature and can mimic key assessment outputs used to inform management and advice on fishing opportunities. Utility of the IBM is demonstrated by simulating the population consequences of several key management scenarios based on those implemented by the European Commission, including short-term bans on pelagic trawling in spawning areas, commercial and recreational catch limits and increasing the minimum conservation reference size. The IBM has potential to complement the annual stock assessment in managing European sea bass because it models individual movement, environmental drivers and emergent spatial distribution, thereby providing enhanced predictions of management strategy outcomes that could inform spatial advice on fishing opportunities and policy.

\section{Keywords}

European sea bass; individual-based model; management; spatially explicit 


\section{Introduction}

The Northern stock of European sea bass (Dicentrarchus labrax), covering the North Sea, English Channel, Celtic Sea and Irish Sea, is an important target for both commercial and recreational fisheries, with recreational fisheries responsible for over a quarter of the total catch (Hyder et al., 2018; Radford et al., 2018). The commercial fishery developed rapidly in the late 1970s (Pawson et al., 2005) and fishing mortality has increased since then reaching a maximum in 2013. As a result of fishing pressure and poor recruitment, the stock has declined drastically over the past decade and was estimated below management reference points in 2018 (ICES, 2018a). Emergency management measures were introduced in 2015 and legislation is becoming increasingly strict for both recreational and commercial fisheries, including restrictions on the amount of catch, such as daily bag limits on the number of fish taken per recreational fisher and monthly catch limits for commercial vessels, as well as spatial restrictions such as closed seasons and areas (European Commission, 2015a). To make decisions about which measures will be most effective, there is a need to explore the impact of these measures on the current population and make predictions about how they will affect the population in the future.

Sea bass in the northern stock are relatively slow growing, reaching up to 30 years of age and maturing at around 4 to 6 years (Pawson and Pickett, 1996). They have a complex lifecycle with a pelagic larval phase, juveniles then occupy nursery grounds, generally located within inshore areas, before joining the adult population. Mature sea bass follow extensive migrations between inshore summer feeding areas and winter pre-spawning and spawning areas. Movement between areas is rapid and occurs around April to May, at the end of spawning, and between October and December as females seek warmer water (Pawson et al., 2007, 1987). There is strong evidence that 
feeding areas are specific to local populations (Doyle et al., 2017; Pawson et al., 2008), while spawning generally occurs in the Celtic and southern North Seas between February and June. The geographic extent of spawning is thought to be bounded by a minimum temperature of $9^{\circ} \mathrm{C}$ meaning it can expand as the season progresses and in warmer years (Pickett and Pawson, 1994). The pelagic phase lasts between 2 to 4 months (Jennings and Ellis, 2015) during which time dispersal brings a proportion of the larvae to the vicinity of nursery grounds in estuaries, saltmarshes and other sheltered coastal sites (Beraud et al., 2018).

The Northern sea bass stock is assessed by the International Council for the Exploration of the Sea (ICES) using Stock Synthesis (SS3; Methot and Wetzel, 2013): an analytical size- and age-structured population model. In broad terms, SS3 includes: 1) a population dynamics model, which simulates growth, mortality and recruitment; 2) an observation model which relates the population dynamics to available data; and 3) a statistical model which estimates parameters to maximise the goodness of fit between population model and data. Stock status is determined by comparing outputs from SS3 to reference points considered consistent with obtaining maximum sustainable yield (MSY, i.e. the largest long-term yield that can be taken without causing the stock to collapse) and keeping the stock within safe biological limits (termed precautionary reference points). Outputs from SS3 are used as a starting point to project the population effects of various catch scenarios, with the objective of setting catch advice for the following year (ICES, 2018a). SS3 includes a "multi-area" configuration, where a stock can be sub-divided into multiple geographical units (Methot and Wetzel, 2013). However, this implicit spatial structure is limited in its ability to forecast the consequences of spatially explicit management measures. A more appropriate approach for evaluating spatially explicit management measures is to 
develop models that can make predictions about the distribution of a stock, and hence capture the localized effects of those measures on the appropriate subset of the population.

The most widely used approach for predicting spatial distributions of fish populations is with correlative species distribution models (SDMs; Robinson et al., 2017). SDMs relate the abundance and/or occurrence of fish to environmental variables and can be used to generate maps of habitat suitability. While habitat suitability is an important determinant of a stock's spatial distribution, the degree to which potential habitat can be utilised depends on constraints to movement such as physical barriers and dispersal capacities. One way to account for these constraints is by explicitly simulating the movement of individuals. This can be achieved using individual-based models (IBMs) where animal populations are represented by their constituent individuals in spatially explicit landscapes, and population dynamics and structure emerge from the actions of all individuals (Grimm and Railsback, 2005; van der Vaart et al., 2016). As well as allowing for explicit simulation of individual movements, IBMs can incorporate population dynamics models such as those in SS3 (e.g. growth and mortality modules). The difference is that the population dynamics go from being sizeand/or age-based, to size-, age- and individual-based to allow for variability among individuals of the same age or size group. As such, IBMs are now widely used to simulate the spatial distribution of fish populations (e.g. Heinänen et al., 2018; Watkins and Rose, 2017), as well as population size and structure (Boyd et al., 2018, 2020; Bueno-Pardo et al., 2020; Politikos et al., 2015).

We present a spatially explicit IBM that simulates the population dynamics and spatial distribution of the Northern sea bass stock. The model landscape consists of dynamic maps of sea surface temperature (SST) that influence growth, movement, migrations 
and spawning. Spatial distribution is simulated using a combination of known temperature preferences and extensive information from tagging studies. The population dynamics are based on conventional stock assessment techniques and are conditioned on SS3 parameterisations for the Northern sea bass stock. We compare the IBM's predictions of abundance, spawning (SSB) and total stock biomass (TSB) to those from SS3 and the predicted spatial distribution to independent data from commercial catches. Finally, we demonstrate the utility of the IBM by predicting the population consequences of several management scenarios, including: (1) short-term bans on pelagic trawling in offshore spawning areas; (2) commercial and recreational catch limits; and (3) increasing in the minimum conservation reference size (MCRS).

\subsubsection{Overview}


146 The model environment is composed of a grid landscape of $36 \times 38$ patches (grid 147 cells), representing the area from $9^{\circ} \mathrm{E}$ to $9^{\circ} \mathrm{W}$ and $48^{\circ} \mathrm{N}$ to $57.5^{\circ} \mathrm{N}$, where each group 148 of four patches represents an ICES statistical rectangle (rectangles of 30 min latitude 149 by 1 degree longitude used for gridding of data). Sea patches are characterised by dynamic variable sea surface temperature (SST; a key driver of sea bass dynamics; Pickett and Pawson, 1994; TRACE Section 4) and variables for patch type (coastal patches are those within an ICES rectangle that intersects land, offshore patches are all remaining sea patches, spawning patches are described in Section 2.1.3.1 and nursery patches are those south of $54^{\circ} \mathrm{N}$ intersecting land; Beraud et al., 2017; Kelley, 1988), ICES division (4.b, 4.c, 7.a, 7.d, 7.e or 7.fg) and region (North Sea, English Channel, Celtic Sea or Irish Sea). ICES divisions and regions are mutually exclusive while patch types are not, as all nursery patches are coastal, and all spawning patches are offshore (Figure 1). For simplicity, we assume the population is closed to migrations outside the model domain.

To render model run times tractable, the sea bass population is modelled with superindividuals (hereafter termed individuals) each of which represents many fish with identical state variables (Scheffer et al., 1995). Individuals are characterised by the number of fish represented, age, cohort age (integer age of the year class), life stage (juvenile $<6$ years or adult/mature aged $6+$ ), length, weight, location, swimming speed and daily direction changes, spawning trigger and counter, mortality rates (natural, commercial inshore and offshore- and recreational-fishing) and the division they have an affinity to feed in. Sea bass variables and processes are described further in Section 2.1.3.

The model runs in daily time steps from $1^{\text {st }}$ January 1985 to the $31^{\text {st }}$ December 2014 , 170 just prior to the implementation of emergency management measures in 2015 . In each 
time step, individuals follow five main processes, all constructed from several submodels: growth, mortality, movement, aging and reproduction. Figure 2 provides a conceptual overview of the processes and submodels represented in the IBM.

\subsubsection{Initialisation}

The population is initialised using numbers-at-age data estimated for 1985 (ICES, 2018b; TRACE Section 3) apportioned into ten super-individuals per cohort (year class). Individuals in the juvenile life-stage that are less than four years old are distributed randomly in nursery patches, juveniles 4-6 years in coastal patches and the adult life-stage in pre-spawning areas (coastal patches in division 7.e; Figure 1). Each mature individual is assigned a random ICES division for which it has an affinity to feed.

\subsubsection{Processes}

Here we describe the model processes. Detailed descriptions of submodels, parameters, input data and underlying assumptions are provided in the TRACE document. Aside from patch updates (Section 2.1.3.1) the following processes relate to sea bass individuals and, unless otherwise stated, are executed daily in the following order:

\subsubsection{Patch updates}

The SST of patches are updated monthly using data from the Operational Sea Surface Temperature and Sea Ice Analysis data set (OSTIA; http://marine.copernicus.eu/ ) averaged over the month. Between February-May any offshore patches south of $54^{\circ} \mathrm{N}$ with an SST value between $9-15^{\circ} \mathrm{C}$ are assigned as spawning patches (Beraud et al., 2018; Kelley, 1988; Thompson and Harrop, 1987). 
Each individual increases its length according to Fabens (1965) manipulation of the von Bertalanffy growth equation adjusted for the effects of temperature on growth (TRACE Section 2). The mean weight of fish within an individual is calculated from length following the allometric equation. Both equations are parameterised with the same parameter values used in the stock assessment (ICES, 2018b).

\subsubsection{Mortality}

201

The number of fishes within an individual decline exponentially due to natural and fishing mortality. Natural mortality occurs due to factors such as predation and disease and is taken as a fixed instantaneous rate of 0.24 (year $^{-1}$; ICES, 2018b; TRACE Section 3) converted to a daily rate.

Commercial fisheries operating in the Northern management unit are considered to have two distinct components catching different subsets of the population throughout their life and migration cycles: (1) offshore fisheries on pre-spawning and spawning bass; and (2) small-scale inshore fisheries catching immature bass and mature bass returning to coastal feeding areas (ICES, 2012). Partial fishing mortality estimates by age and metier derived from the stock assessment outputs (ICES, 2018b) were therefore aggregated to give annual fishing mortality rates-at-age for three broad fleets: commercial inshore, commercial offshore and recreational (TRACE Section 3). Fishing mortality varies across patches such that when an individual occupies an inshore patch only the commercial inshore and recreational fishing mortality rates are applied, and when an individual occupies an offshore patch only the offshore fishing mortality rate is applied. Commercial fishing mortality rates are raised to account for the fact that fishing does not occur all year round. The commercial offshore fleet is 
assumed to operate predominantly between November and April (ICES, 2012) and the commercial inshore fleet between April and November. The total fishing mortality applied to individuals is then the sum of fishing mortality from the relevant fleets converted to a daily rate. Any individuals with less than one fish after applying natural or fishing mortality die and are removed from the simulation.

\subsubsection{Movement}

The sustained swimming speed of individuals is calculated from length and the aspect ratio of the caudal fin (Sambilay Jr, 1990), and is adjusted for the effects of temperature on swimming speed (TRACE Section 2). Speeds in kilometres per hour are converted to patches per day assuming 12 hours swimming per day. The number of times individuals change direction is taken as the smallest integer such that quotient of speed and the number of direction changes is less than 0.25 , chosen to minimise overlap of individuals and land without restricting movement (TRACE Section 3).

Mature individuals follow two types of migration based on hypotheses drawn from 20 years of mark-recapture studies conducted around England and Wales, and corroborated by recent electronic data storage tag (DST) experiments: spawning migrations to offshore regions and feeding migrations to coastal divisions (Figure 1 and Figure 3). Pawson et al. $(2007,1987)$ hypothesised that these seasonal migrations are a function of temperature. Adult bass migrate to pre-spawning areas in the western English Channel between October and December as females seek water warmer than $9^{\circ} \mathrm{C}$. Spawning then starts offshore in the Celtic Sea and western English Channel from February and spreads east as the water attains $9^{\circ} \mathrm{C}$ (Thompson and Harrop, 1987). It was inferred that spent fish moved to specific feeding grounds around April 241 to May after spawning (Pawson and Pickett, 1996). Movement between areas 
appeared rapid (de Pontual et al., 2019) with most migrations being made along the coast (Pickett and Pawson, 1994). Here, the migration submodels incorporate both directed movements towards a destination (migratory) and random localised movements (non-migratory) once the destination has been reached.

Within the IBM, spawning migrations occur from October to May and are triggered by temperature either when a mature individual neighbours a spawning patch (see Section 2.1.3.1) or the patch occupied has an SST below $9^{\circ} \mathrm{C}$ (Figure 3a). Once a spawning migration has been triggered, the individual follows a decision hierarchy that transports it along the coast towards the western English Channel (division 7.e in Figure 1), moving offshore if and when neighbouring a spawning patch (Figure 3b; TRACE Figure 4). To do this, each 'step' the individual choses a neighbour patch based on patch type and direction, preferentially: (1) moving towards an offshore the Celtic Sea and English Channel but can also occur in other areas when temperature conditions are satisfied. Once offshore, the individual moves randomly within spawning patches until assumed spent after spawning, which occurs either after spending 60 days offshore or on 1 June, whichever occurs first (Figure 3a).

When a mature individual is not following a spawning migration, it defaults to a feeding migration, which transports the individual to the coastal division it has an affinity to feed in. Each 'step' the individual again choses a neighbour patch based on patch type and direction where, assuming the individual starts offshore, the migration broadly follows: (1) move directly towards the coast then (2) move towards a coastal neighbour on route to the correct region and division (Figure 3b; TRACE Figure 5). The individual moves randomly once it has reached its assigned feeding division. 
267 Evidence from tagging studies suggest that juveniles remain within discrete nursery grounds for the first few years of life and disperse primarily during the adolescent phase (Pickett et al., 2004; Pickett and Pawson, 1994). Juvenile individuals therefore follow a random walk constrained to discrete nursery areas (brown patches in Figure 1) when aged less than four years and widen their movements to all coastal patches (green and brown patches in Figure 1) when aged four to six.

\subsubsection{Aging}

Juvenile individuals become sexually mature at six years (TRACE Section 4). Given sea bass disperse primarily during the adolescent phase, individuals adopt the division occupied at the time of maturity as the coastal division for which they have an affinity to feed, which may not be the same as the parent stock or close to their nursery ground (Pickett et al., 2004; Pickett and Pawson, 1994).

\subsubsection{Reproduction}

Newly recruited fish enter the model in June-September (Jennings and Ellis, 2015). Ten juvenile individuals enter the IBM each year with the number of individuals entering in a month being proportional to the number of spawning individuals (mature individuals occupying offshore patches) earlier in the year (Figure 4A). Recruiting individuals are distributed in coastal divisions according to the distribution of spawning individuals via connectivity probabilities derived from a particle tracking IBM coupled with hydrodynamics (Beraud et al., 2018; TRACE Section 3; Figure 4B). Given the lack of stock-recruitment relationship for sea bass (see Section 4), the number of fish represented by recruiting individuals is taken as the number of age 0 fish from the ICES numbers-at-age data (ICES, 2018b). Each individual is assumed 100 days old when it settles in a nursery area (Beraud et al., 2018; Jennings and Ellis, 2015). 


\subsection{MODEL TESTING}

\subsubsection{Conditioning and validation}

To check conditioning of the population dynamics, numbers, spawning stock biomass (SSB) and total stock biomass (TSB) from the IBM were compared to the same quantities from the stock assessment (ICES, 2018b), which represents the best available knowledge on status of the stock. To account for stochasticity, the IBM was run ten times and differences between median IBM output and the assessment quantified. Cohort (integer) ages were fed into calculations of biomass to account for the differing temporal resolution of the IBM and stock assessment.

In the absence of a suitable survey (see Section 4), spatial patterns from a single run of the IBM were compared to commercial catch data for 2009-2014 from the Scientific, Technical and Economic Committee for Fisheries (STECF; https://stecf.jrc.ec.europa.eu/). Equivalent catches from the IBM were calculated using the standard equation (Baranov, 1918; TRACE Section 2) for commercial inshore and commercial offshore fleets.

\subsubsection{Sensitivity analysis}

Local sensitivity analyses were conducted to explore how sensitive IBM outputs were to changes in model parameters and inputs. To assess temporal sensitivity, five simulations were performed for $10 \%$ increases and decreases in each model parameter, holding all other parameters at their baseline values, and compared to five baseline simulations. Median numbers and biomasses were averaged over the timeseries, with the result of each perturbation presented as a percentage of the baseline. Spatial sensitivity was assessed similarly, but with a single run of the IBM providing replicates at each parameter level and results taken over the last five years. The 
spatial distribution of the catch for each perturbation is approximated and summarised by the centre of gravity (Woillez et al., 2007) while the mean correlation coefficient between perturbed and baseline catch quantifies the degree of change in spatial pattern with each perturbation.

\subsection{MODEL APPLICATIONS}

To demonstrate potential for management, the IBM was projected forward under a range of management strategies based on those implemented by the European Commission in 2015 and 2016. As future conditions are unknown, scenarios were explored based on current environmental conditions and fishing practices: (1) SST data for 2015-2016 were obtained from the OSTIA database while SST data for subsequent years were taken as the average of 2014-2016, (2) recruitment was taken as the $25 \%, 50 \%$ and $75 \%$ quantile of recruitment estimates from the assessment (ICES, 2018b), (3) natural mortality was assumed constant at 0.24 and (4) unless otherwise stated, fishing level and exploitation pattern for each fleet was assumed the same as in 2014; the last year prior to implementation of management measures.

Management strategies for forward projections included: (1) a short-term ban on trawling in offshore areas; (2) commercial and recreational catch limits and restrictions; and (3) an increase in the minimum conservation reference size (MCRS) (Table 1). All scenarios were implemented by adjusting the fishing mortality rates applied to the appropriate individuals based on length or location in relation to a fleet restriction. For simplicity, we do not consider redistribution of fishing mortality from individuals that are protected by a management scenario to those that are not.

The IBM was run ten times for each management scenario and a series of constant fishing mortalities. A set of hindcast simulations provided the starting point for 
projections and ensured performance was not influenced by initial conditions.

Management strategies were evaluated based on mean SSB in: (1) the first 10 years of projections to inform on short-term recovery; and (2) the last 10 years of projections to inform on long-term stock status, i.e. once equilibrium has been reached.

\section{Results}

\subsection{MODEL TESTING}

Abundances from the IBM and stock assessment match well with almost perfect correlation and low root-mean square (RMS) difference (Table 2; Figure 5), largely due to conditioning of the IBM on the SS3 assessment. Biomass patterns match well but with differences for SSB due to differences in the way maturity is modelled (lengthbased in SS3 and age-based in the IBM). The IBM estimates TSB to be an average of $6 \%$ lower over the time series than the assessment because SS3 uses an alternative parameterisation of the von Bertalanffy growth equation (Methot and Wetzel, 2013; TRACE Section 6). This perceived bias is somewhat concealed for SSB due to the differences in modelling maturity.

The IBM correctly predicts the majority of catch is taken in the English Channel (ICES divisions 7.d-e) with a correlation of $0.32(p<0.01)$ between mean catch from the IBM and STECF data over the whole stock area (Figure 6; $0.24-0.40$ over individual years; TRACE Section 8). The IBM tends to overestimate catch in the Celtic (7.f-h) and Irish (7.a) Seas and underestimate catch in the North Sea (4.b-c; Figure 7; see Section 4).

Sensitivity of abundance and biomasses to most parameter values and inputs was low, with $10 \%$ changes in these quantities mostly resulting in changes of $<10 \%$ in 
model outputs (Table 3). Biomasses were sensitive to the von Bertalanffy growth and length-weight parameters, known with some confidence, and all three outputs showed some sensitivity to natural mortality. Of the stock assessment inputs, IBM outputs were most sensitive to recruitment and least sensitive to commercial offshore fishing mortality (see Section 4). Spatial distribution and pattern were most sensitive to the aspect ratio of the caudal fin and rate coefficient of the growth equation, both of which contribute to calculation of swimming speed (TRACE Section 2). However, for both metrics the effects were small with the displacement in centre of gravity less than the length of a patch for most perturbations $($ mean $=18 \mathrm{~km}$; maximum $=55 \mathrm{~km}$ for a $10 \%$ increase in the rate coefficient; TRACE Section 7) and the correlation between perturbed and baseline catch remaining above 0.8 (Table 3).

\subsection{MODEL APPLICATIONS}

Forward projections under constant fishing mortality showed median SSB to equilibrate after approximately 25 years (Figure 8), informing the choice of a 35-year projection period.

Even with the associated reductions in fishing mortality, management scenario trajectories show SSB to continue its decrease in the first years of the projection because the year classes reaching maturity are not large enough to replace losses from the existing spawning stock. The future recruitment assumption begins to impact the spawning stock in 2021, from which time age structure improves and SSB increases to equilibrium (Figure 9). Results show setting commercial limits to be the most effective strategy for short-term rebuilding of the spawning stock and increasing the MCRS to be the most effective strategy for long-term health (Table 4), which is unsurprising given that these strategies are applied throughout the management area 
and potentially protect a larger proportion of the stock. We note that our median recruitment assumption is larger than any recruitment observed since 2009 and likely contributes to long-term success of the increase in MCRS because there are more smaller individuals to protect once the age structure of the stock improves.

\section{Discussion}

The IBM was conditioned on the stock assessment, which represents the best available knowledge on status of the Northern sea bass stock. It can mimic the population dynamics component of SS3 and, given appropriate catchability parameters, could also produce simulated observations in a manner similar to SS3. Where the IBM falls short is in the ability to statistically fit such modelled observations to data from commercial fishing fleets or fishery-independent surveys, and for this reason cannot substitute SS3 for the annual stock assessment. Rather, the IBM has potential to complement SS3 because it models the movement and distribution of sea bass, essential for predicting the population consequences of spatial management strategies.

Model validation has taken the 'pattern-oriented approach' (Grimm and Railsback, 2005). While it would be attractive to use objective methods such as approximate Bayesian computation (van der Vaart et al., 2016, 2015) these will be challenging to implement because of long model run times ( 10 minutes).

Pawson et al. (1987) formulated hypotheses on the movement and migrations of sea bass from data for 5959 fish tagged around England and Wales, with a follow-on exercise for a further 4959 fish confirming the validity of the hypothesis 20 years later (Pawson et al., 2007). Without knowledge on the mechanisms informing these largescale migrations, our submodels simulate these hypothesised movements based on 
a set of empirical rules. Recent studies deploying electronic data storage tags (DSTs) confirm the migratory nature of sea bass and have the potential to further elucidate this behaviour (de Pontual et al., 2019; O’Neill et al., 2018; Quayle et al., 2009). In particular, DSTs record both the temperature and depth experienced by fish at regular intervals, making it possible to geolocate and reconstruct movement trajectories (Woillez et al., 2016) that could inform a statistical movement model within the IBM. However, DST returns to date are low and, given specific DST release sites and high fidelity of sea bass to localised feeding areas (Doyle et al., 2017; Pawson et al., 2008), likely do not contain sufficient information on all local populations in the management area we consider. Temperature triggers in the IBM allow some modelling of behavioural traits and provide mechanisms for responding to changes in sea surface temperature, e.g. delayed spawning in warmer years and increased spawning in the southern North Sea (Pawson et al., 2007); however, as DST returns increase, it would be desirable to devise fully mechanistic movement submodels.

Some IBMs for small pelagic species relate movement to an underlying distribution of food via satellite measurements of chlorophyll or model based estimates of zooplankton (Boyd et al., 2020; Politikos et al., 2015). However, the distribution of sea bass is not as closely related to primary production and the plankton due to its higher trophic level and exploitation of many different food sources.

Ideally, the spatial aspect of the IBM would be validated against data from a fisheryindependent survey providing an unbiased estimator of the underlying population. However, sea bass are not captured well by survey gears (Walker et al., 2017) and surveys that do capture bass either only target recruits or cover just a small portion of the stock area (ICES, 2018c). Without a suitable survey, we take reported catch as a proxy for the underlying distribution. However, the distribution of fishing effort does not 
necessarily match the underlying distribution of fish. In recent years the majority of monthly sea bass landings in the UK are from ports in the English Channel and from under $10 \mathrm{~m}$ vessels $(\mathrm{MMO}, 2018)$. These smaller vessels are likely to travel a limited distance from port to fishing grounds, creating a limited area from which bass captures are reported. Additionally, socio-economic factors, weather and legislation influence when and where vessels fish (Sainsbury et al., 2018). This combination of factors may provide explanation for the discrepancies between IBM and STECF catch data, especially in the Celtic sea. We note that, beyond splitting annual fishing mortality rates between fleets, effort is not modelled explicitly in this study and the current focus is modelling the spatiotemporal distribution of the population rather than regenerating catch. While it would be desirable to spatialise fishing mortality, time-series of reliable fishing effort data are lacking. Most smaller boats employ a variety of gears and take small amounts of sea bass as bycatch, meaning that fishing effort is not directly proportional to the fishing mortality exerted on sea bass.

450 Experimental studies on swimming speeds of bass focused on juveniles (e.g. parameterised for sea bass (Sambilay Jr, 1990). This coupled with direct movement (Pickett and Pawson, 1994), results in rapid migration of individuals to spawning areas in the Celtic Sea and English Channel and increased settlement of juveniles in coastal divisions with high connectivity to these areas, likely contributing to the overestimation of catch in divisions 7.a,f-g.

Estimating recruitment of fish stocks is notoriously difficult and may be influenced by several confounding factors in addition to the size of the spawning stock. Given the high influence of environmental conditions on survivability and growth of juveniles (Bento et al., 2016) there is no clear stock-recruitment (S-R) relationship for European 
sea bass. The SS3 assessment uses a Beverton-Holt S-R with high steepness, mimicking a segmented regression that gives average recruitment with high uncertainty (ICES, 2018c). Given the apparent lack of S-R for sea bass, we used the assessment estimates as input to the IBM, and project the quantiles of these estimates when testing management strategies. This approach suggests that age structure of the stock may be important in determining how well a management strategy performs and highlights the importance of modelling recruitment. Furthermore, decoupling recruitment from the modelled spawning stock likely contributed to the low sensitivity of model outputs to offshore fishing mortality and poor performance of an offshore fishing ban. This is because any benefits from protecting the mature portion of the stock from their highest source of fishing mortality are not realised in modelled recruitment.

An interesting possibility is that the IBM could be used to predict recruitment without an S-R. Recruitment can be broadly decomposed into the number of eggs produced by the spawning stock and the number of eggs that survive. There have been several attempts to represent these processes with IBMs, often using a bioenergetics-based approach (Bartsch et al., 2004; Boyd et al., 2018; Bueno-Pardo et al., 2020; Politikos et al., 2015; Shin and Cury, 2001). When predictions of egg production and early survival are combined, it is possible to obtain emergent predictions of recruitment.

Spawning stock biomass (SSB) is an important metric for determining the state of fish stocks and informing on management actions. The fact our IBM can mimic estimates of SSB that are robust to uncertainty in parameter values make it an ideal tool for testing the performance of fishing strategies and informing management. In particular, our study includes many elements of a shortcut management strategy evaluation (MSE; Punt et al., 2016) in that we model population dynamics, observations (e.g. 
catch) and implementation of management strategies without performing an

487

488

489

490

491

492

493

494

495

496

497

498

499

500

501

502

503

504

505

506

507

508

509 assessment within our simulations. However, given long model run times, it would be difficult to consider the full range of uncertainties typically modelled in an MSE. Given the current status of the stock, we focused on performance statistics related to recovery and long-term health, but the IBM could be used to assess other aspects of performance such as yield maximisation, risk reduction and TAC (total allowable catch) stability.

This first implementation of the IBM offers a tool to assess how technical measures applied to subsets of the population, through fleet or spatial restrictions, may impact the stock. For example, our management simulations suggest technical measures applied throughout the management area, such as an increase in MCRS or limits for commercial fleets, are more effective than localised measures, such as inshore recreational restrictions or bans on offshore trawling. Our movement and recruitment assumptions limit the validity of the model to past and current environmental conditions; further research into these areas would increase robustness of predictions in novel environmental conditions and reliability of management strategy outcomes.

\section{Acknowledgements}

We would like to thank Kate Collingridge, Roi Martinez and Gwladys Lambert for helping source data; Serena Wright and Kirsty Bradley for discussions on movement of sea bass; Volker Grimm and Steve Railsback for commenting on an early version of the model and ODD; Mitchell Lennan, Yang Qu, and Isioma Tongo for their help at an early stage of the project. This work was funded by the UK Department of Environment, Food and Rural Affairs.

\section{References}


Augusiak, J., Van den Brink, P.J., Grimm, V., 2014. Merging validation and evaluation of ecological models to "evaludation": A review of terminology and a practical approach.

Ecol. Modell. 280 , $117-128$. https://doi.org/10.1016/j.ecolmodel.2013.11.009

Baranov, F.I., 1918. On the question on the biological basis of fisheries. Nauchn. Issled. Ikhtiologicheskii Inst. Izv 1, 81-128.

Bartsch, J., Coombs, S.H., Reid, D., 2004. Simulation of mackerel (Scomber scombrus) recruitment with an individual-based model and comparison with field data. Fish. Ocean. 13, 380-391. https://doi.org/10.1111/j.13652419.2004.00306.x

Bento, E.G., Grilo, T.F., Nyitrai, D., Dolbeth, M., Pardal, M.Â., Martinho, F., 2016. Climate influence on juvenile European sea bass (Dicentrarchus labrax, L.) populations in an estuarine nursery: A decadal overview. Mar. Environ. Res. 122, 93-104. https://doi.org/10.1016/j.marenvres.2016.09.011

Beraud, C., Molen, J. Van Der, Armstrong, M., Hunter, E., Fonseca, L., Hyder, K., 2018. The influence of oceanographic conditions and larval behaviour on settlement success-the European sea bass Dicentrarchus labrax (L.). ICES J. Mar. Sci. 75, 455-470. https://doi.org/10.1093/icesjms/fsx207

Boyd, R., Roy, S., Sibly, R., Thorpe, R., Hyder, K., 2018. A general approach to incorporating spatial and temporal variation in individual-based models of fish populations with application to Atlantic mackerel. Ecol. Modell. 382, 9-17. https://doi.org/10.1016/j.ecolmodel.2018.04.015

Boyd, R.J., Sibly, R., Hyder, K., Walker, N., Thorpe, R., Roy, S., 2020. Simulating the summer feeding distribution of Northeast Atlantic mackerel with a mechanistic 
individual-based model. Prog. Oceanogr. 183, 102299.

Bueno-Pardo, J., Petitgas, P., Kay, S., Huret, M., 2020. Integration of bioenergetics in an individual-based model to hindcast anchovy dynamics in the Bay of Biscay.

Claireaux, G., 2006. Effect of temperature on maximum swimming speed and cost of

de Pontual, H., Lalire, M., Fablet, R., Laspougeas, C., Garren, F., Martin, S., Drogou, M., Woillez, M., 2019. New insights into behavioural ecology of European seabass off the West Coast of France : implications at local and population scales. ICES

Doyle, T.K., Haberlin, D., Clohessy, J., Bennison, A., Jessopp, M., 2017. Localised residency and inter- annual fidelity to coastal foraging areas may place sea bass at risk to local depletion. Sci. Rep. 1-9. https://doi.org/10.1038/srep45841

European Commission, 2015a. COUNCIL REGULATION (EU) 2015/960 of 19 June 2015 amending Regulation (EU) 2015/104 as regards certain fishing opportunities. Off. J. Eur. Union L157, 1-19.

European Commission, 2015b. COUNCIL REGULATION (EU) 2015/104 of 19 January 2015 fixing for 2015 the fishing opportunities for certain fish stocks and groups of fish stocks, applicable in Union waters and, for Union vessels, in certain non-Union waters, amending Regulation (EU) No 43. Off. J. Eur. Union L22, 1150. 
European Commission, 2015c. COMMISSION IMPLEMENTING REGULATION (EU) 2015/1316 of 30 July 2015 derogating from Council Regulation (EC) No 850/98, as regards the minimum conservation reference size for sea bass (Dicentrarchus labrax). Off. J. Eur. Union L203, 9-10.

Fabens, A.J., 1965. Properties and fitting of the von Bertalanffy growth curve. Growth 29, 265-289.

Grimm, V., Augusiak, J., Focks, A., Frank, B.M., Gabsi, F., Johnston, A.S.A., Liu, C., Martin, B.T., Meli, M., Radchuk, V., Thorbek, P., Railsback, S.F., 2014. Towards better modelling and decision support: Documenting model development, testing, and analysis using TRACE. Ecol. Modell. 280, 129-139. https://doi.org/10.1016/j.ecolmodel.2014.01.018

Grimm, V., Berger, U., Bastiansen, F., Eliassen, S., Ginot, V., Giske, J., Goss-Custard, J., Grand, T., Heinz, S.K., Huse, G., Huth, A., Jepsen, J.U., Jørgensen, C., Mooij, W.M., Müller, B., Pe'er, G., Piou, C., Railsback, S.F., Robbins, A.M., Robbins, M.M., Rossmanith, E., Rüger, N., Strand, E., Souissi, S., Stillman, R.A., Vabø, R., Visser, U., DeAngelis, D.L., 2006. A standard protocol for describing individualbased and agent-based models. Ecol. Modell. 198, 115-126. https://doi.org/10.1016/j.ecolmodel.2006.04.023

Grimm, V., Berger, U., DeAngelis, D.L., Polhill, J.G., Giske, J., Railsback, S.F., 2010. The ODD protocol: A review and first update. Ecol. Modell. 221, 2760-2768. https://doi.org/10.1016/j.ecolmodel.2010.08.019

Grimm, V., Railsback, S.F., 2005. Individual-based Modeling and Ecology. Princeton University Press, Princeton.

Heinänen, S., Chudzinska, M.E., Brandi Mortensen, J., Teo, T.Z.E., Rong Utne, K., 
Doksæter Sivle, L., Thomsen, F., 2018. Integrated modelling of Atlantic mackerel distribution patterns and movements: A template for dynamic impact assessments. Ecol. Modell. 387, 118-133. https://doi.org/10.1016/j.ecolmodel.2018.08.010

Hyder, K., Weltersbach, M.S., Armstrong, M., Ferter, K., Townhill, B., Ahvonen, A., Arlinghaus, R., Baikov, A., Bellanger, M., Birzaks, J., Borch, T., Cambie, G., de Graaf, M., Diogo, H.M.C., Dziemian, Ł., Gordoa, A., Grzebielec, R., Hartill, B., Kagervall, A., Kapiris, K., Karlsson, M., Kleiven, A.R., Lejk, A.M., Levrel, H., Lovell, S., Lyle, J., Moilanen, P., Monkman, G., Morales-Nin, B., Mugerza, E., Martinez, R., O’Reilly, P., Olesen, H.J., Papadopoulos, A., Pita, P., Radford, Z., Radtke, K., Roche, W., Rocklin, D., Ruiz, J., Scougal, C., Silvestri, R., Skov, C., Steinback, S., Sundelöf, A., Svagzdys, A., Turnbull, D., van der Hammen, T., van Voorhees, D., van Winsen, F., Verleye, T., Veiga, P., Vølstad, J.H., Zarauz, L., Zolubas, T., Strehlow, H. V., 2018. Recreational sea fishing in Europe in a global context-Participation rates, fishing effort, expenditure, and implications for monitoring and assessment. Fish Fish. 19, 225-243. https://doi.org/10.1111/faf.12251

ICES, 2018a. Sea bass (Dicentrarchus labrax) in divisions 4.b-c , 7.a, and 7.d-h (central and southern North Sea, Irish Sea, English Channel, Bristol Channel, and Celtic Sea), in: Report of the ICES Advisory Committee. pp. 1-10.

ICES, 2018b. Report of the Working Group on Celtic Seas Ecoregion (WGCSE), 9-18 May 2018, Copenhagen, Denmark. ICES CM 2018/ACOM:13. 1887 pp.

ICES, 2018c. Report of the Benchmark Workshop on Seabass (WKBASS), 20-24 February 2017 and 21-23 February 2018, Copenhagen, Denmark. ICES CM 
606

607

608

609

610

611

612

613

614

615

616

617

618

619

620

621

622

623

624

625

626

627

ICES, 2012. Report of the Working Group on assessment of New MoU species (WGNEW), 5-9 March 2012. ICES CM 2012/ACOM:20. 258 pp.

Jennings, S., Ellis, J.R., 2015. Bass (Moronidae), in: Heesen, H.J.L., Daan, N., Ellis, J.R. (Eds.), Fish Atlas of the Celtic Sea, North Sea, and Baltic Sea: Based on International Research Vessel Data. KNNV Publishing, The Netherlands, pp. 324-327.

Kelley, D.F., 1988. The importance of estuaries for sea-bass, Dicentrarchus labrax (L.). J. Fish Biol. 33, 25-33. https://doi.org/10.1111/j.1095-8649.1988.tb05555.x

Methot, R.D., Wetzel, C.R., 2013. Stock synthesis: A biological and statistical framework for fish stock assessment and fishery management. Fish. Res. 142, 86-99. https://doi.org/10.1016/j.fishres.2012.10.012

MMO, 2018. Marine Management Organisation - Latest dataset - UK and foreign vessels landings by UK port and UK vessel landings abroad: 2014, 2015, 2016 and 2017 (year to date) - GOV.UK [WWW Document].

O’Neill, R., Ó Maoiléidigh, N., McGinnity, P., Bond, N., Culloty, S., 2018. The novel use of pop-off satellite tages (PSATs) to investigate the migratory behaviour of European sea bass Dicentrarchus labrax. J. Fish Biol. 92, 1404-1421. https://doi.org/10.1111/jfb.13594

Pawson, M.G., Brown, M., Leballeur, J., Pickett, G.D., 2008. Will philopatry in sea bass, Dicentrarchus labrax, facilitate the use of catch-restricted areas for management of recreational fisheries? Fish. Res. 93, 240-243. https://doi.org/10.1016/j.fishres.2008.03.002 
628 Pawson, M.G., Pickett, G.D., 1996. The Annual Pattern of Condition and Maturity in

629

630

631

632

633

634

635

636

637

638

639

640

641

642

643

644

645

646

647

648

649

650

651 Bass, Dicentrarchus Labrax, in Waters Around England and Wales. J. Mar. Biol. Assoc.

United

Kingdom

76 ,

107-125. https://doi.org/10.1017/S0025315400029040

Pawson, M.G., Pickett, G.D., Kelley, D.F., 1987. The distribution and migrations of bass, Dicentrarchus labrax L., in waters around England and Wales as shown by tagging. J. Mar. Biol. Assoc. United Kingdom 67, 183-217. https://doi.org/10.1017/S0025315400026448

Pawson, M.G., Pickett, G.D., Leballeur, J., Brown, M., Fritsch, M., 2007. Migrations, fishery interactions, and management units of sea bass (Dicentrarchus labrax) in Northwest Europe. ICES J. Mar. Sci. 64, 332-345. https://doi.org/10.1093/icesjms/fsl035

Pawson, M.G., Pickett, G.D., Smith, M.T., 2005. The role of technical measures in the recovery of the UK sea bass (Dicentrarchus labrax) fishery 1980-2002. Fish. Res. 76, 91-105. https://doi.org/10.1016/j.fishres.2005.06.006

Pickett, G.D., Kelley, D.F., Pawson, M.G., 2004. The patterns of recruitment of sea bass, Dicentrarchus labrax L. from nursery areas in England and Wales and implications for fisheries management. Fish. Res. 68, 329-342. https://doi.org/10.1016/j.fishres.2003.11.013

Pickett, G.D., Pawson, M.G., 1994. Sea bass biology, exploitation and conservation. Chapman and Hall, London.

Politikos, D., Somarakis, S., Tsiaras, K., Giannoulaki, M., Petihakis, G., Machias, A., Triantafyllou, G., 2015. Simulating anchovy's full life cycle in the northern Aegean Sea (eastern Mediterranean): A coupled hydro-biogeochemical-IBM model. Prog. 
Punt, A.E., Butterworth, D.S., de Moor, C.L., De Oliveira, J.A.A., Haddon, M., 2016. Management strategy evaluation: Best practices. Fish Fish. 17, 303-334. https://doi.org/10.1111/faf.12104

Quayle, V.A., Righton, D., Hetherington, S., Pickett, G., 2009. Observations of the Behaviour of European Sea Bass (Dicentrarchus labrax) in the North Sea, Tagging and Tracking of Marine Animals with Electronic Devices, Reviews: Methods and Technologies in Fish Biology and Fisheries. Springer Netherlands, Dordrecht. https://doi.org/10.1007/978-1-4020-9640-2

Radford, Z., Hyder, K., Zarauz, L., Mugerza, E., Ferter, K., Prellezo, R., Strehlow, H.V., Townhill, B., Lewin, W.-C., Weltersbach, M.S., 2018. The impact of marine recreational fishing on key fish stocks in European waters. PLoS One 13, e0201666. https://doi.org/10.1371/journal.pone.0201666

Robinson, N.M., Nelson, W.A., Costello, M.J., Sutherland, J.E., Lundquist, C.J., 2017. A Systematic Review of Marine-Based Species Distribution Models (SDMs) with Recommendations for Best Practice. Front. Mar. Sci. 4, 1-11. https://doi.org/10.3389/fmars.2017.00421

Sainsbury, N.C., Genner, M.J., Saville, G.R., Pinnegar, J.K., O’Neill, C.K., Simpson, S.D., Turner, R.A., 2018. Changing storminess and global capture fisheries. Nat. Clim. Chang. 8, 655-659. https://doi.org/10.1038/s41558-018-0206-x

Sambilay Jr, V., 1990. Interrelationships between swimming speed, caudal fin aspect ratio and body length of fishes. Fishbyte $8,16-20$.

Scheffer, M., Baveco, J.M., DeAngelis, D.L., Rose, K.A., van Nes, E.H., 1995. Super- 

individuals a simple solution for modelling large populations on an individual basis. Ecol. Modell. 80, 161-170. https://doi.org/10.1016/0304-3800(94)00055-M

Schmolke, A., Thorbek, P., DeAngelis, D.L., Grimm, V., 2010. Ecological models supporting environmental decision making: A strategy for the future. Trends Ecol. Evol. 25, 479-486. https://doi.org/10.1016/j.tree.2010.05.001

Shin, Y., Cury, P., 2001. Exploring fish community dynamics through size-dependent trophic interactions using a spatialized individual-based model. Aquat. Living Resour. 14, 65-80. https://doi.org/10.1016/S0990-7440(01)01106-8

Thompson, B.M., Harrop, R.T., 1987. The distribution and abundance of bass (Dicentrarchus labrax) eggs and larvae in the English Channel and Southern North Sea. J. Mar. Biol. Assoc. United Kingdom 67, 263. https://doi.org/10.1017/S0025315400026588

van der Vaart, E., Beaumont, M.A., Johnston, A.S.A., Sibly, R.M., 2015. Calibration and evaluation of individual-based models using Approximate Bayesian Computation. Ecol. Modell. 312, 182-190. https://doi.org/10.1016/j.ecolmodel.2015.05.020

van der Vaart, E., Johnston, A.S.A., Sibly, R.M., 2016. Predicting how many animals will be where: How to build, calibrate and evaluate individual-based models. Ecol. Modell. 326, 113-123. https://doi.org/10.1016/j.ecolmodel.2015.08.012

Walker, N.D., Maxwell, D.L., Le Quesne, W.J.F., Jennings, S., 2017. Estimating efficiency of survey and commercial trawl gears from comparisons of catch-ratios. ICES J. Mar. Sci. 74, 1448-1457. https://doi.org/10.1093/icesjms/fsw250

Watkins, K.S., Rose, K.A., 2017. Simulating individual-based movement in dynamic 
Ecol.

Modell.

356 ,

$59-72$. https://doi.org/10.1016/j.ecolmodel.2017.03.025

700

701

702

703

704

705

706

707

708

709

710

711 Supporting information

712

Wilensky, U., 1999. NetLogo. Centre for Connected Learning and Computer-based Modelling. Northwestern University, Evanstonm IL. http://ccl.northwestern.edu/netlogo/

Woillez, M., Fablet, R., Ngo, T.T., Lalire, M., Lazure, P., de Pontual, H., 2016. A HMMbased model to geolocate pelagic fish from high-resolution individual temperature and depth histories: European sea bass as a case study. Ecol. Modell. 321, 1022. https://doi.org/10.1016/j.ecolmodel.2015.10.024

Woillez, M., Poulard, J.-C., Rivoirard, J., Petitgas, P., Bez, N., 2007. Indices for capturing spatial patterns and their evolution in time, with application to European hake (Merluccius merluccius) in the Bay of Biscay. ICES J. Mar. Sci. 64, 537550. https://doi.org/10.1093/icesjms/fsm025

Additional Supporting Information may be found in the online version of this article. 


\begin{tabular}{|c|c|c|}
\hline Scenario & Description & Implementation \\
\hline \multicolumn{3}{|c|}{ Constant fishing mortality } \\
\hline$F=0$ & No fishing & Multiplier of 0 applied to Fs of all individuals (fishing mortality switched off) \\
\hline$F=F_{\mathrm{MSY}}$ & $F_{4-15}=0.203($ ICES, 2018c) & $\begin{array}{l}\text { Multiplier of } 0.781 \text { applied to } F s \text { of all individuals } \\
\qquad \frac{0.203}{F(2014)_{4-15}}=0.781\end{array}$ \\
\hline$F=F(2014)$ & $F=F(2014)$ & Multiplier of 1 applied to $F$ s of all individuals \\
\hline \multicolumn{3}{|c|}{ Management scenarios } \\
\hline Offshore ban & $\begin{array}{l}\text { Short-term ban on pelagic trawling to protect the spawning stock } \\
\text { (European Commission, 2015b) }\end{array}$ & Commercial offshore fishing mortality switched off between 1 Jan-30 Apr each year $\left(F_{\mathrm{C}_{0}}=0\right)$ \\
\hline Increase MCRS & $\begin{array}{l}\text { Increase in the minimum size from } 36 \text { to } 42 \mathrm{~cm} \text { (European } \\
\text { Commission, 2015c) }\end{array}$ & Fishing mortality on individuals $<42 \mathrm{~cm}$ switched off \\
\hline Recreational limits & Six months no take followed by 1 fish bag limit & $\begin{array}{l}\text { Multiplier of } 0.282 \text { applied to recreational fishing mortalities }\left(F_{\mathrm{Ri}}\right)(\text { this annual multiplier accounts for } \\
\text { both management measures; see ICES, 2018c) }\end{array}$ \\
\hline Catch \& release & All fish caught recreationally are released & Multiplier of 0.099 applied to recreational fishing mortalities $\left(F_{\mathrm{Ri}}\right)($ ICES, 2018c) \\
\hline Commercial limit & $\begin{array}{l}\text { Monthly catch limits for commercial fleets (European Commission, } \\
\text { 2015a) }\end{array}$ & $\begin{array}{l}\text { Target fishing mortality is set following a simple harvest control rule (ICES, 2018a), converted to } \\
\text { commercial catch with the standard Baranov equation and divided by } 12 \text {. } \\
\qquad F_{\text {tar }} \begin{cases}F_{M S Y}, & S S B \geq M S Y B_{\text {trigger }} \\
F_{M S Y} \times \frac{S S B}{M S Y B_{\text {trigger }}}, \quad S S B<M S Y B_{\text {trigger }}\end{cases} \\
\text { Commercial inshore and offshore fishing mortality switched off for the remainder of the month once } \\
\text { limit is exceeded }\left(F_{\mathrm{Co}} \& F_{\mathrm{Ci}}\right) \text {. }\end{array}$ \\
\hline
\end{tabular}




\begin{tabular}{|l|l|l|l|l|}
\hline & \multicolumn{1}{|c|}{$\boldsymbol{E}$} & $\boldsymbol{E}(\%)$ & $\bar{E}(\%)$ & $\boldsymbol{E}^{\prime}(\%)$ \\
\hline Numbers & 1.00 & 0.68 & -0.49 & 0.47 \\
\hline SSB & 0.93 & 8.32 & 0.39 & 8.31 \\
\hline TSB & 1.00 & 6.17 & -5.73 & 2.30 \\
\hline
\end{tabular}

717 Table 2: Correlation coefficient $(r)$ and normalised RMS difference $(E)$ resolved into bias $(\bar{E})$ and

718 variability $\left(E^{\prime}\right)$ components for IBM outputs compared to those of the stock assessment for the hindcast

719 period (1985-2014). 


\begin{tabular}{|c|c|c|c|c|c|c|c|c|c|c|c|c|}
\hline Parameter & Value & Quality & N- & $\mathrm{N+}$ & SSB- & SSB+ & TSB- & TSB+ & d- & d+ & r- & $\mathbf{r +}$ \\
\hline \multicolumn{13}{|l|}{ Growth } \\
\hline Asymptotic length $\left(L^{\infty}\right)$ & 84.55 & 4 & 0.0 & 0.0 & -26.8 & 32.8 & $\begin{array}{ll}-26.8 \\
-1\end{array}$ & 32.8 & 10.1 & 10.0 & 0.92 & 0.90 \\
\hline Growth rate coefficient $(k)$ & 0.096699 & 4 & 0.0 & 0.0 & -17.4 & 17.9 & -19.2 & 20.5 & 29.8 & 55.4 & 0.89 & 0.84 \\
\hline Age at length $0\left(t_{0}\right)$ & -0.73 & 4 & 0.0 & 0.0 & -1.4 & 1.4 & -2.5 & 2.6 & 14.7 & 21.6 & 0.91 & 0.92 \\
\hline Activation energy $\left(E_{g}\right)$ & $5.2 \mathrm{E}-21$ & 1 & 0.0 & 0.0 & 0.0 & 0.0 & 0.0 & 0.0 & 20.9 & 6.5 & 0.91 & 0.93 \\
\hline Reference temperature $\left(T_{g}\right)$ & 12 & 1 & 0.0 & 0.0 & 0.0 & 0.0 & 0.0 & 0.0 & 22.1 & 21.2 & 0.91 & 0.91 \\
\hline \multicolumn{13}{|l|}{ Weight } \\
\hline Length-weight parameter (a) & $1.3 \mathrm{E}-05$ & 4 & --- & --- & -10.0 & 10.1 & -10.0 & 10.1 & 12.9 & 9.6 & 0.87 & 0.91 \\
\hline Length-weight parameter $(b)$ & 2.969 & 4 & --- & --- & -68.8 & 221.4 & -66.6 & 203.3 & 11.6 & 23.1 & 0.92 & 0.90 \\
\hline \multicolumn{13}{|l|}{ Swimming } \\
\hline Aspect ratio of the caudal fin $(A)$ & 1.76 & 2 & 0.0 & 0.0 & 0.1 & 0.1 & 0.1 & 0.1 & 31.2 & 29.0 & 0.89 & 0.89 \\
\hline Activation energy $\left(E_{s}\right)$ & $5.03 E-21$ & 2 & 0.0 & 0.0 & 0.0 & 0.0 & 0.0 & 0.0 & 8.0 & 38.4 & 0.91 & 0.90 \\
\hline Activation temperature $\left(T_{s}\right)$ & 6 & 2 & 0.0 & 0.0 & 0.0 & 0.0 & 0.0 & 0.0 & 16.3 & 1.7 & 0.92 & 0.92 \\
\hline Swimming hours $(h)$ & 12 & 1 & 0.0 & 0.0 & 0.0 & 0.1 & 0.0 & 0.0 & 13.4 & 23.5 & 0.90 & 0.89 \\
\hline Maximum patch direction $\left(P_{\max }\right)$ & 0.25 & 1 & 0.0 & 0.0 & -0.1 & 0.1 & 0.0 & 0.1 & 15.4 & 33.2 & 0.91 & 0.89 \\
\hline \multicolumn{13}{|l|}{ Mortality } \\
\hline Natural mortality $(M)$ & 0.24 & 2 & 6.3 & -5.5 & 19.2 & -15.4 & 15.5 & -12.8 & 14.1 & 31.3 & 0.90 & 0.87 \\
\hline \multicolumn{13}{|l|}{ Stock assessment inputs } \\
\hline Commercial inshore mortality $\left(F_{\mathrm{Ci}}\right)$ & 1 & 3 & 0.5 & -0.5 & 3.9 & -3.5 & 2.6 & -2.4 & 23.5 & 9.9 & 0.88 & 0.90 \\
\hline Commercial offshore mortality $\left(F_{\mathrm{Co}}\right)$ & 1 & 3 & 0.0 & 0.0 & 0.3 & -0.4 & 0.2 & -0.3 & 13.1 & 8.1 & 0.90 & 0.92 \\
\hline Recreational mortality $\left(F_{\mathrm{Ri}}\right)$ & 1 & 3 & 0.3 & -0.3 & 2.0 & -1.9 & 1.3 & $\begin{array}{c}-1.3 \\
\end{array}$ & 7.7 & 11.7 & 0.92 & 0.91 \\
\hline Recruitment $(R)$ & 1 & 3 & -9.3 & 9.3 & -6.9 & 6.9 & -7.7 & 7.7 & 16.4 & 10.7 & 0.92 & 0.92 \\
\hline
\end{tabular}


Table 3: Sensitivity of abundance (N), spawning stock biomass (SSB), total stock biomass (TSB), spatial distribution (d) and spatial pattern ( $r$ ) to $10 \%$ decreases displacement of the centre of gravity $(\mathrm{km})$ and spatial pattern by correlation coefficient with a baseline run. Quality gives the estimated quality of empirical knowledge used to set each parameter value: 5 means high certainty while 1 means low certainty (TRACE Section 3). 


\begin{tabular}{|c|c|c|c|c|c|c|}
\hline \multirow[b]{3}{*}{ Scenario } & \multicolumn{6}{|c|}{ Mean SSB (tonnes) } \\
\hline & \multicolumn{3}{|c|}{ Short term (2015-2024) } & \multicolumn{3}{|c|}{ Long term (2041-2050) } \\
\hline & $\mathbf{R} 50 \%$ & R25\% & $\mathbf{R 7 5} \%$ & $\mathbf{R 5 0} \%$ & $\mathbf{R} 25 \%$ & $\mathbf{R 7 5} \%$ \\
\hline \multicolumn{7}{|c|}{ Constant fishing mortality } \\
\hline$F=0$ & 16511 & & & 42129 & & \\
\hline$F=F_{M S Y}$ & 8670 & & & 12813 & & \\
\hline$F=F(2014)$ & 7507 & & & 10148 & & \\
\hline \multicolumn{7}{|c|}{ Management scenarios } \\
\hline Offshore ban & 7745 & 7072 & 8218 & 10653 & 5700 & 14133 \\
\hline Increase MCRS & 8676 & 7813 & 9282 & 13155 & 7038 & 17451 \\
\hline Recreational limits & 8224 & 7513 & 8723 & 11726 & 6272 & 15556 \\
\hline Catch \& release & 8421 & 7699 & 8929 & 12196 & 6524 & 16179 \\
\hline Commercial limit & 9035 & 8266 & 9568 & 12743 & 7498 & 16734 \\
\hline
\end{tabular}

725 Table 4: Results of projections under constant $F$ and management strategies. Rxx\% relate to assumed

726 recruitment, with the median highlighted in bold for each scenario. Mean SSB is the mean of the median

727 SSB across replicates for the given projection period. 


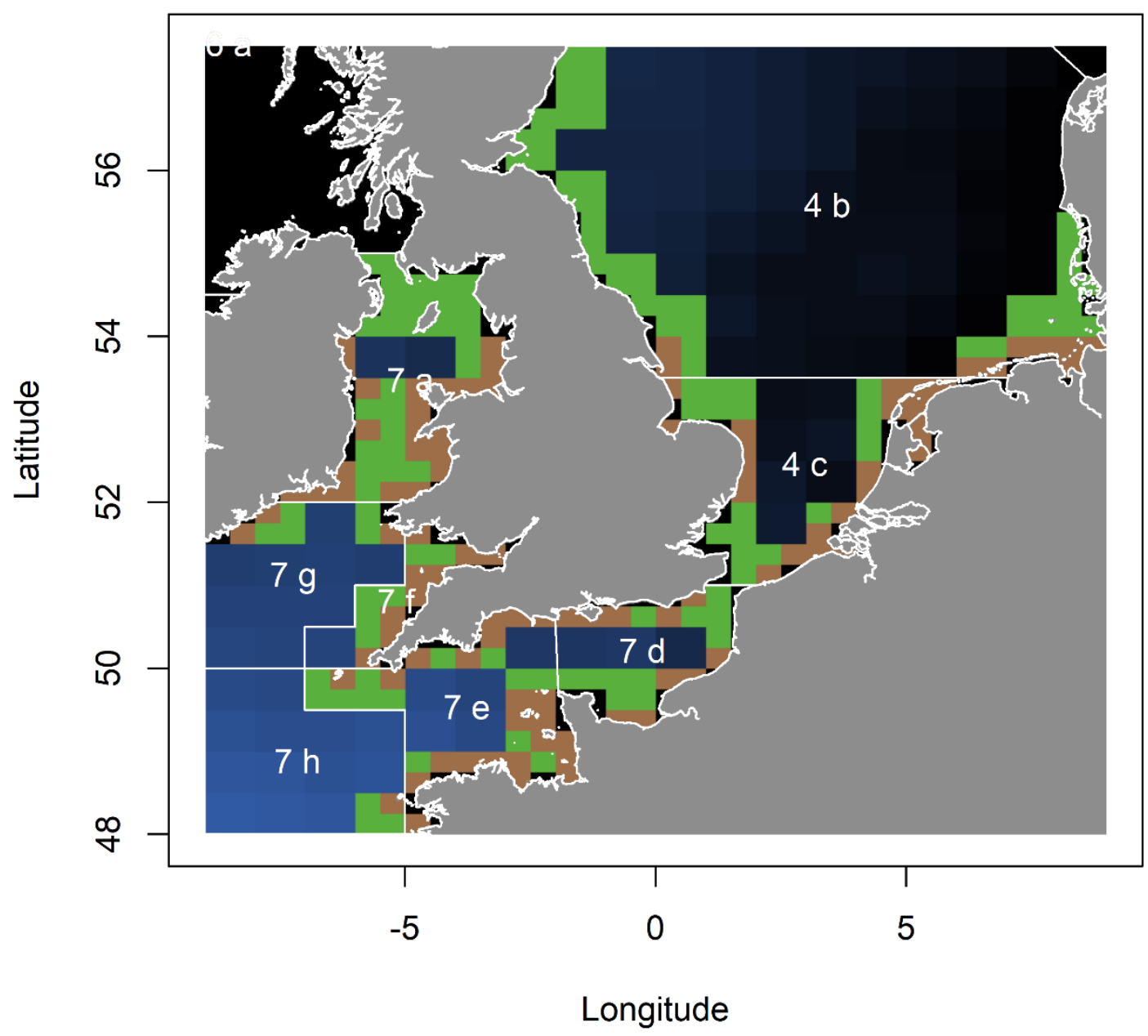

728

729 Figure 1: The model interface at set-up (1 ${ }^{\text {st }}$ January 1985). Coastal patches are represented in green,

730 nursery patches (also coastal) in brown and offshore patches in blue (with the blue gradient from dark

731 to light representing increasing SST; monthly averages). ICES divisions spanning the northern

732 assessment unit are superimposed. Regions for offshore spawning are defined as follows: North Sea $733=4 . \mathrm{b}-\mathrm{c} ;$ English Channel $=7 . \mathrm{d}-\mathrm{e}$, Celtic Sea $=7 . \mathrm{f}-\mathrm{h}$ and Irish Sea $=7 . \mathrm{a}$. 


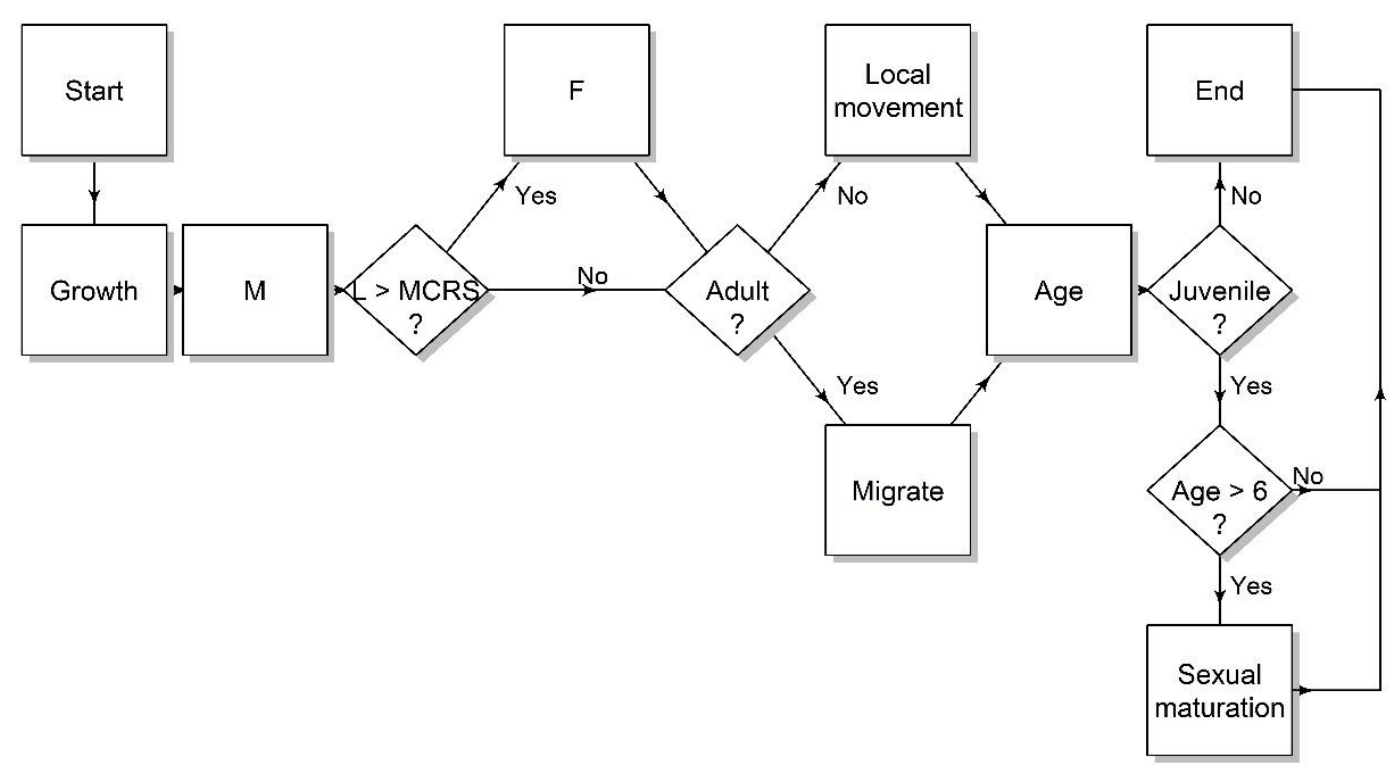

734

735 Figure 2: Conceptual model showing the processes that individuals follow each daily time-step. $\mathrm{M}$ is

736 natural mortality, $\mathrm{F}$ is fishing mortality (including commercial inshore and offshore and recreational), $\mathrm{L}$

737 is length and MCRS is the minimum conservation reference size. 


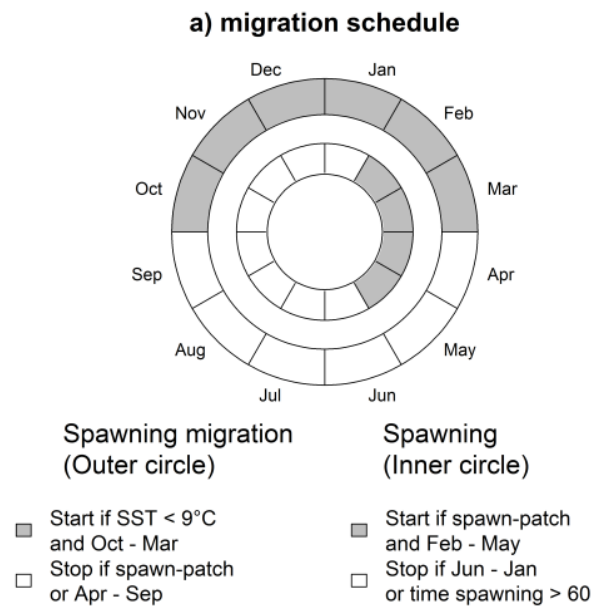

739

740 Figure 3: (a) Schedule for spawning migrations. Outer circle: migration to (pre-)spawning areas is

741 triggered by SST and can take place between October and March. Inner circle: spawning takes place

742 within offshore spawning patches appearing February-May. b) Mature individuals migrate following the

743 hypotheses of Pawson et al. $(1987,2007)$. Arrows show movement around the coast to and from the

744 English Channel and Celtic Sea (although movement offshore can occur anywhere temperature

745 conditions are satisfied) with black arrow heads representing the spawning migration and red arrow

746 heads the feeding migration.

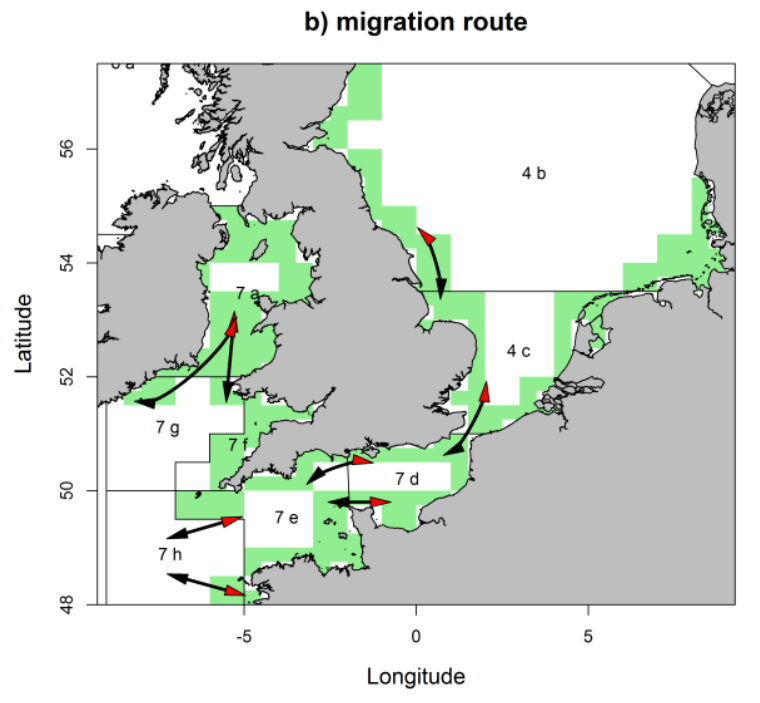




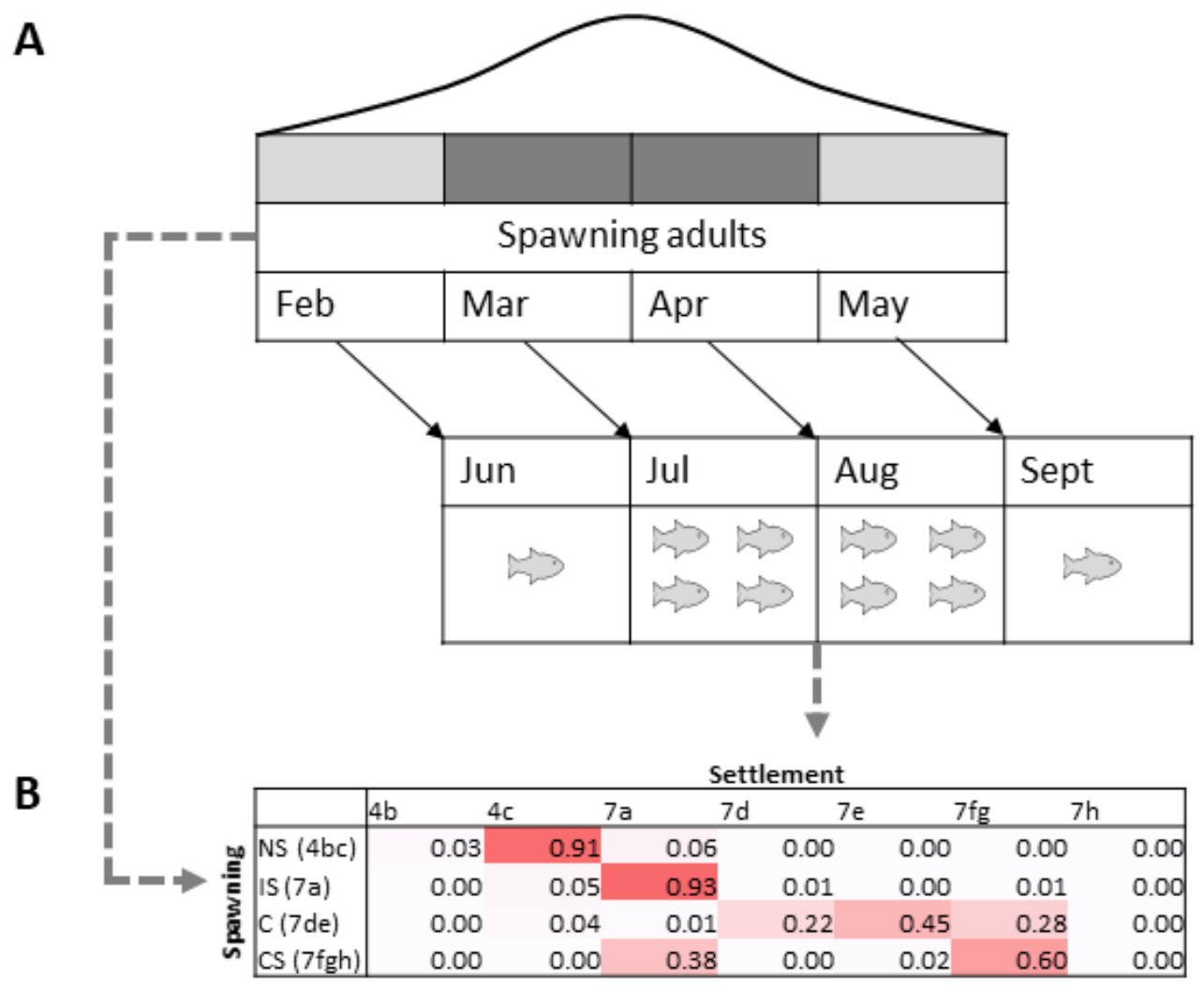

748 Figure 4: Schematic showing how the spatiotemporal distribution of recruiting individuals follows from 749 the spatiotemporal distribution of spawning individuals. A: Ten individuals enter the IBM proportional to 750 the number of spawning individuals in the corresponding month. B: Connectivity between offshore 751 spawning regions and coastal settlement divisions. Each cell gives the probability of settling in a coastal 752 division given the distribution of spawning individuals in offshore regions the corresponding month. 753 Shading represents the strength of connectivity. Modified from Beraud et al. (2017). 

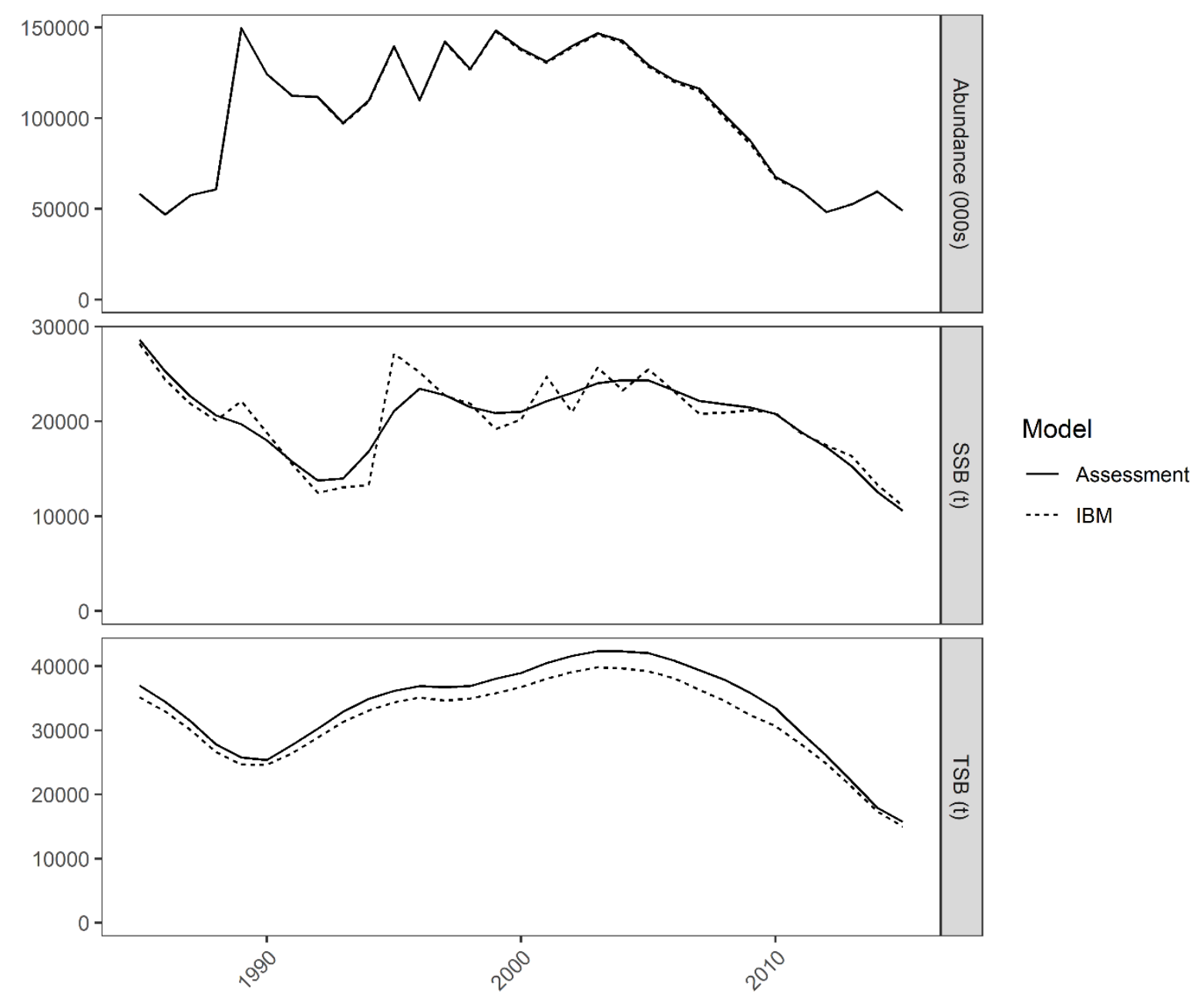

Figure 5: Abundance, SSB and TSB as estimated by the stock assessment and IBM. 

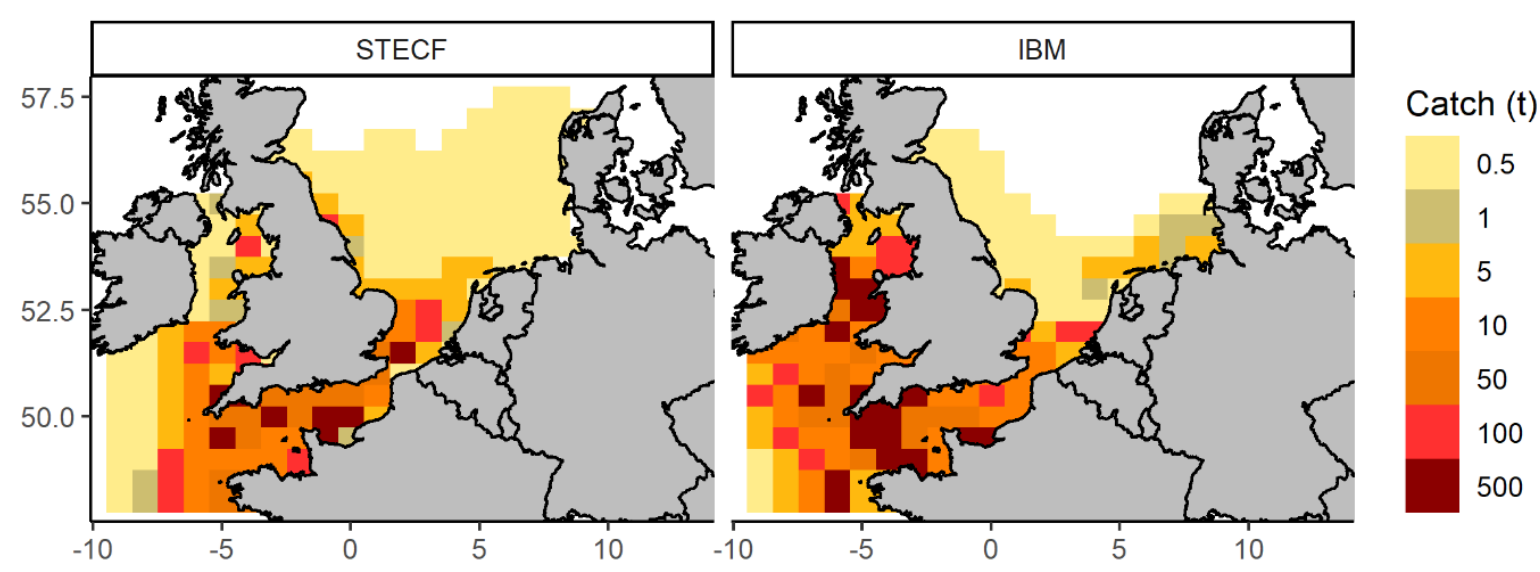

757

758 Figure 6: Comparison of mean catch from 2009-2014 as recorded in the STECF database and 759 estimated by the IBM. Only non-zero catches are plotted because effort is not explicitly represented in 760 the IBM. 


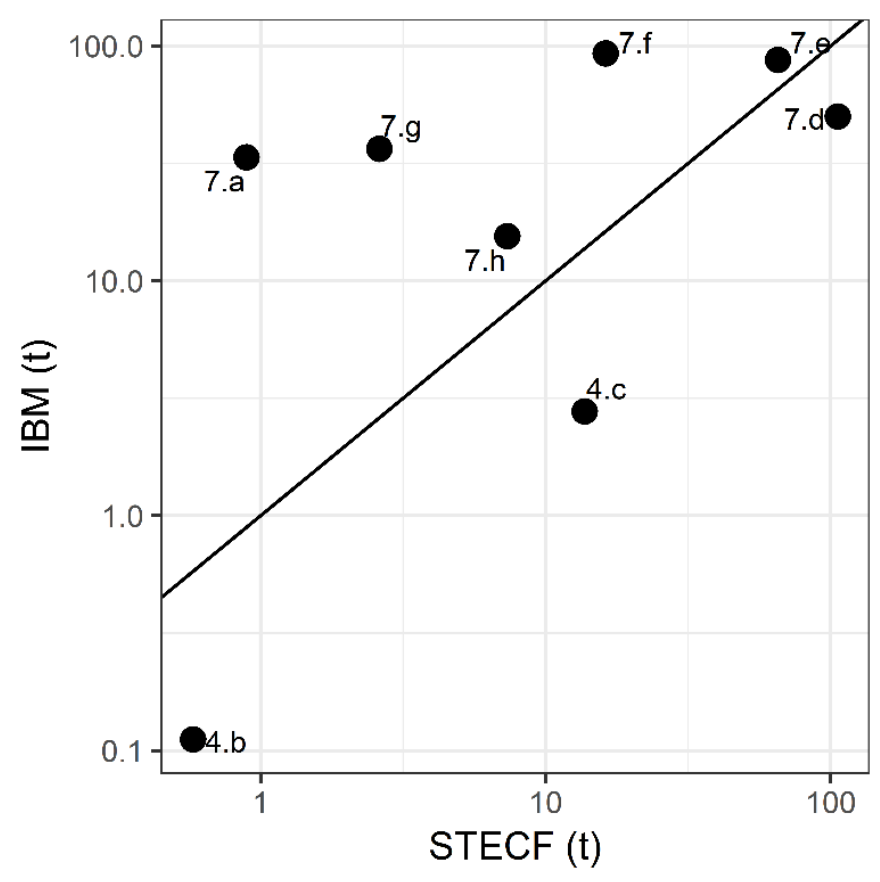

762

763 Figure 7: Comparison of mean catch by ICES division from 2009-2014 as recorded in the STECF database and estimated by the IBM. See Figure 1 for a map of ICES divisions. 


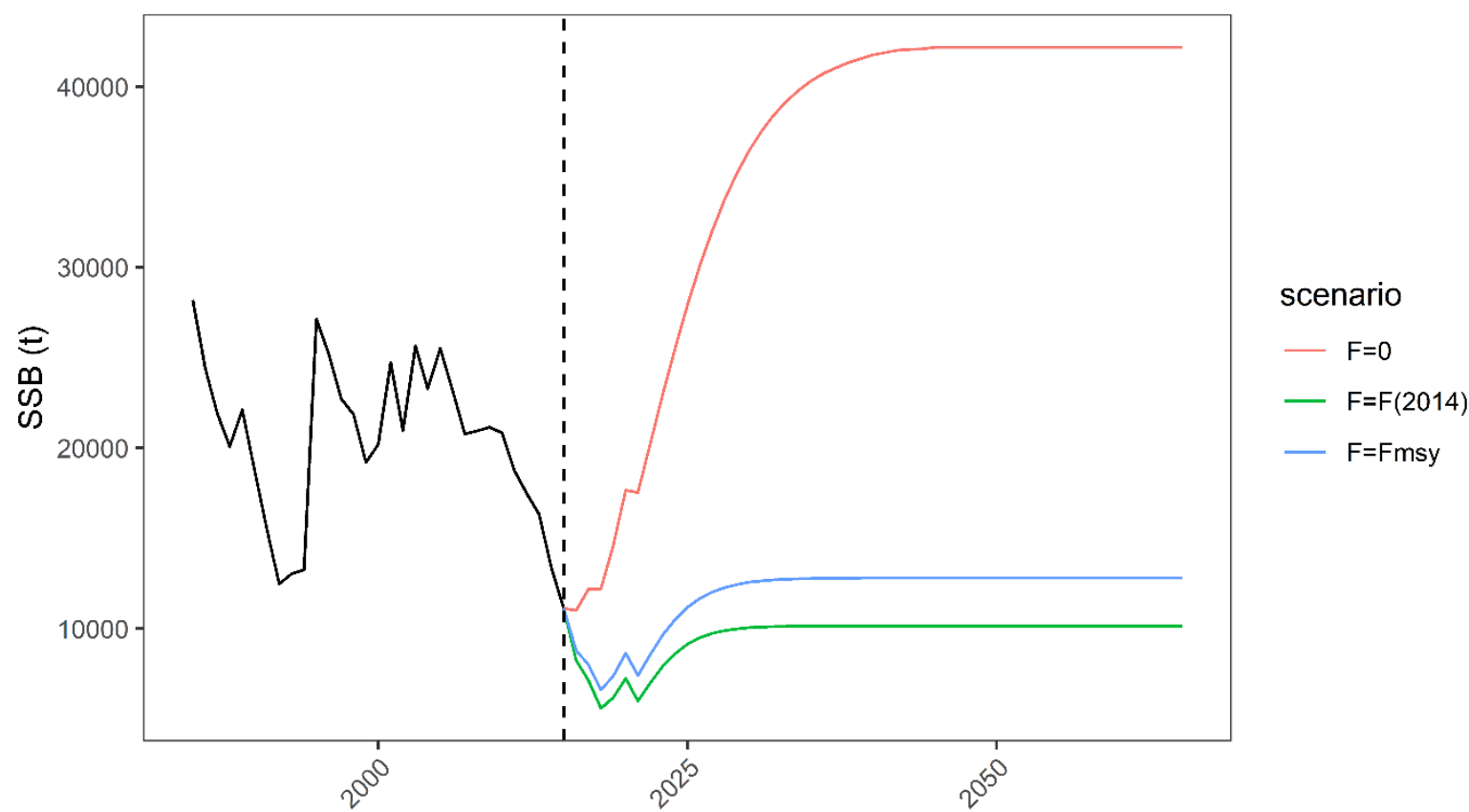

767 Figure 8: Forward 50-year projections of SSB (tonnes) under constant fishing mortality: $F=0$, $768 F=F_{\mathrm{MSY}}=0.203$ (a reference for northern sea bass) and $F=F(2014)=0.260$. The black line shows the median of 10 hindcast simulations, the coloured lines the median for future projections and the dashed line the start of the projection period. 


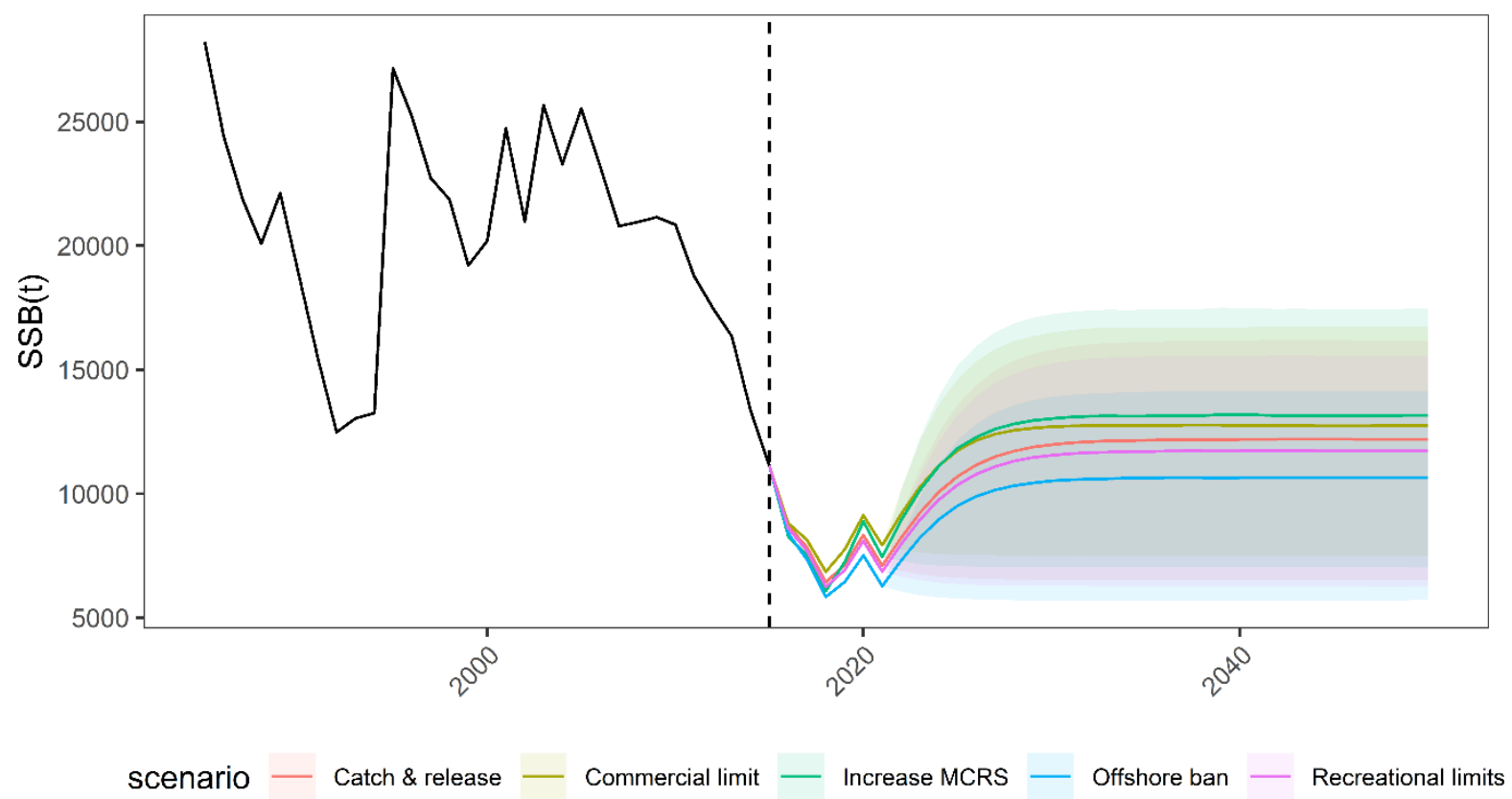

773 Figure 9: Projections under the management scenarios described in Table 1. The black line shows the 774 median of 10 hindcast simulations, the coloured lines and shaded regions median SSB under different 775 recruitment assumptions (median and $25-75 \%$ quantiles respectively) and the dashed line the start of 776 the projection period. 